\title{
Association between Risk Factors and Carotid Enlargement
}

\author{
Ryuichi Kawamoto, Hitomi Tomita, Yuichiro Oka and Nobuyuki Ohtsuka
}

\begin{abstract}
Objective The aim of this study was to evaluate the influence of conventional cardiovascular risk factors on the degree of adaptive response of the carotid arterial wall to atherosclerotic disease.

Patients and Methods We evaluated the diameter and intima-media thickness (IMT) of common carotid artery (CCA) by ultrasonography in 351 men aged 70.3 (range, 14-97) years and 474 women aged 75.6 (range, 19-103) years in the medical department of Seiyo Municipal Nomura Hospital. We assessed cross-sectionally the relationships between CCA diameter and IMT and cardiovascular risk factors by gender.

Results In multiple linear regression analyses, after controlling for traditional cardiovascular risk factors, a significant correlation was found between CCA diameters and age $(\mathrm{p}=0.034)$, body mass index (BMI) $(\mathrm{p}<$ $0.001)$, smoking status $(\mathrm{p}=0.039)$, alcohol consumption $(<0.001)$ and uric acid (UA) $(\mathrm{p}=0.021)$ in men, and between CCA diameters and age $(<0.001)$, BMI $(\mathrm{p}<0.001)$, systolic blood pressure (SBP) $(\mathrm{p}=0.013)$ and antihypertensive drug use $(\mathrm{p}=0.005)$ in women. Analysis of covariance showed that the two regression lines between carotid IMT and diameter in those with or without plaque were significantly different in both men ( $\mathrm{F}=$ 16.4; $\mathrm{p}<0.001)$ and women $(\mathrm{F}=15.0 ; \mathrm{p}<0.001)$. After adjustment for carotid IMT and plaque, associations with carotid diameters still persisted for age $(\mathrm{p}<0.001)$, BMI $(\mathrm{p}<0.001)$, smoking status $(\mathrm{p}=0.006)$, alcohol consumption $(\mathrm{p}<0.001)$ and SBP $(\mathrm{p}=0.001)$ in men, and age $(\mathrm{p}=0.005)$, BMI $(\mathrm{p}<0.001)$, SBP $(\mathrm{p}=0.047)$ and UA $(\mathrm{p}=0.001)$ in women.

Conclusion This study shows that the CCA diameters correlated with conventional cardiovascular risk factors including alcohol consumption. These findings suggest that the CCA diameters may reflect the ability of adaptive remodeling to the atherosclerosis before plaque formation and can be an important factor during the development of atherosclerosis.
\end{abstract}

Key words: common carotid artery, atherosclerosis, intima-media thickness, alcohol consumption, carotid enlargement

(DOI: 10.2169/internalmedicine.45.1575)

\section{Introduction}

High-resolution B-mode ultrasonography have recently enabled us to evaluate and detect minimal atherosclerotic lesions in superficially located arteries such as carotid and femoral arteries, and minimal arterial wall abnormalities long before the appearance of structural narrowing and hemodynamic disturbances (1-3). Until now, many B-mode studies have mainly focused on assessment of intima-media thickness (IMT) of the common carotid artery (CCA). Several epidemiological studies have shown a link between IMT and subsequent cardiovascular risk factors in the general population (4-6), and the IMT is clinically considered the surrogate endpoint of cardiovascular disease (7-9). However, some studies have shown that an increased carotid diameter was also independently related to several cardiovascular risk factors and that more attention should be paid as a compensating factor of carotid atherosclerosis (10-12). Unfortunately, few studies have examined whether or not there is a relationship between the carotid diameter and cardiovascular risk factors in Japanese persons (11).

The aim of this study was to investigate the crosssectional associations of carotid structure 〔lumen diameter and intima-media thickness (IMT)] assessed by B-mode ultrasound with conventional cardiovascular risk factors in 
representative sample of inpatients, and compare the adaptation of lumen diameter to IMT and plaque in each conventional cardiovascular risk factor.

\section{Materials and Methods}

\section{Patients}

The subjects were inpatients consecutively admitted to the Medical Department of Seiyo Municipal Nomura Hospital between September 2003 and June 2005. Patients with cardio-renal insufficiency that would affect blood pressure, renal function, lipid and glucose metabolism were excluded. The causes of hospitalization of the participants were circulatory disorders including stroke in 204 cases, respiratory disorders including pneumonia in 162, diabetes mellitus in 112 , digestive disorders in 75 , infections in 41 , neoplasm in 35 , urinary or reproductive organ disorders in 27 , neurological disorders other than stroke in 73 , mental disorders in 19, metabolic disorders in 29 , musculoskeletal and connective tissue disorders in 14, skin and subcutaneous disorders in 7 , hematological disorders in 4, and miscellaneous diseases in 23. Informed consent for the procedure was obtained from each patient. All procedures were approved by the Ethics Committee of Seiyo Municipal Nomura Hospital.

\section{Ultrasound image analysis}

An ultrasonographic evaluation (Hitachi EUB-565, Hitachi Medical CO., Tokyo, Japan or Aloka SSD-2000, ALOKA CO., LTD., Tokyo, Japan) using a 7.5 MHz linear type B-mode probe was performed by a specialist to evaluate sclerotic lesions of the common carotid arteries on a day close to the day of blood biochemistry analysis (within 2 days). Patients were placed in the supine position, and the bilateral carotid arteries were observed obliquely from the anterior and posterior directions. The CCA diameter measurements were made in the portion of the CCA where the wall interfaces are parallel. We measured the minimal distance between the far-wall intima-lumen interface and the near-wall lumen-intima interface of the bilateral CCA about $10 \mathrm{~mm}$ proximal to the bifurcation of the carotid artery as well as the wall thickness near the $10 \mathrm{~mm}$ point on the Bmode monitor, then used the mean value for analysis. The thickness of the IMT was measured on a longitudinal scan of the far wall of the bilateral CCA about $10 \mathrm{~mm}$ proximal to the bifurcation of the carotid artery (as the image at that site is more clearly depicted compared with that of the near wall) $(2,3)$ as well as the wall thickness near the $10 \mathrm{~mm}$ point on the B-mode monitor, then used the mean value for analysis. Carotid plaque was considered as localized thickening and the echo luminance included those equal to high echogenic structures encroaching into the vessel lumen (2, 13).

\section{Various other risk factors}

We measured systolic (SBP) and diastolic blood pressure
Table 1. Clinical and Biochemical Characteristics of Participants by Gender

\begin{tabular}{|c|c|c|c|}
\hline Variable & $\begin{array}{c}\text { Men } \\
\mathrm{N}=351\end{array}$ & $\begin{array}{l}\text { Women } \\
\mathrm{N}=474\end{array}$ & P-value* \\
\hline Age, years & $70.3 \pm 0.7$ & $75.6 \pm 0.5$ & $<0.001$ \\
\hline Body mass indext, $\mathrm{kg} / \mathrm{m}^{2}$ & $22.5 \pm 0.2$ & $22.4 \pm 0.2$ & 0.623 \\
\hline Smoking statusf, pack.years & $27.5 \pm 1.5$ & $1.3 \pm 0.4$ & $<0.001$ \\
\hline Alcohol consumption, drink/day & $2.2 \pm 0.1$ & $0.09 \pm 0.03$ & $<0.001$ \\
\hline Systolic blood pressure, $\mathrm{mmHg}$ & $135.4 \pm 1.2$ & $137.2 \pm 1.0$ & 0.289 \\
\hline Diastolic blood pressure, mmHg & $77.6 \pm 0.7$ & $76.3 \pm 0.6$ & 0.251 \\
\hline Antihypertensive drug use, N (\%) & $151(43.0)$ & $256(54.0)$ & 0.002 \\
\hline Total cholesterol (mg/dl) & $170 \pm 2.3$ & $191 \pm 1.9$ & $<0.001$ \\
\hline Triglyceride, mg/dl & $93.2 \pm 2.8$ & $95.3 \pm 2.3$ & 0.135 \\
\hline LDL-cholesterol, mg/dl & $101.2 \pm 2.0$ & $118.7 \pm 1.6$ & $<0.001$ \\
\hline HDL-cholesterol, mg/dl & $49.9 \pm 0.9$ & $53.5 \pm 0.8$ & $<0.001$ \\
\hline Antilipidemic drug use, $\mathrm{N}(\%)$ & $16(4.6)$ & $36(7.6)$ & 0.083 \\
\hline Uric acid, mg/dl & $5.6 \pm 0.1$ & $5.0 \pm 0.1$ & $<0.001$ \\
\hline Blood glucose, mg/dl & $133.8 \pm 3.2$ & $127.7 \pm 2.8$ & 0.063 \\
\hline Diabetes mellitus, $\mathrm{N}(\%)$ & $101(28.8)$ & $118(24.9)$ & 0.232 \\
\hline Common carotid artery diameter, mm & $6.45 \pm 0.04$ & $6.15 \pm 0.03$ & $<0.001$ \\
\hline Common carotd intima-media thickness, $\mathrm{mm}$ & $0.98 \pm 0.01$ & $0.98 \pm 0.01$ & 0.847 \\
\hline Common carotid plaque, $\mathrm{N}(\%)$ & $156(44.6)$ & $215(45.4)$ & 0.832 \\
\hline atherosclerotic disease, $\mathrm{N}(\%)$ & $137(39.0)$ & $192(40.5)$ & 0.719 \\
\hline Ischemic stroke, $\mathrm{N}(\%)$ & $119(33.9)$ & $159(33.5)$ & 0.941 \\
\hline Ischemic heart disease, $\mathbf{N}(\%)$ & $35(10.0)$ & $48(10.1)$ & 1.000 \\
\hline \multicolumn{4}{|c|}{$\begin{array}{l}\text { Plus-minus values indicate means } \pm \text { standard error. †Body mass index } \\
\text { was calculated using weight in kilograms divided by the square of height in } \\
\text { meters. \#Smoking status: daily consumption (packs) } \times \text { duration of smoking } \\
\text { (years). * Mann-Whitney U-test or } \chi^{2} \text {-test. }\end{array}$} \\
\hline
\end{tabular}

(DBP) in the right upper arm of patients in a seated posture using a standard sphygmomanometer or an automatic oscillometric blood pressure recorder. Height and weight 〔(used calculate body mass index (BMI)] were measured with standard procedure. Cigarette smoking was quantified based on daily consumption and duration of smoking. The usual alcohol consumption per day of beer, sake and the amount of alcohol consumed was calculated by multiplying the consumption of each beverage by its ethanol content, summing all beverages (one drink=12 $\mathrm{g}$ ethanol intake). Body mass index (BMI) was calculated as weight (kilograms) divided by height (meters) squared. For blood biochemistry analyses, total cholesterol (T-C), triglyceride (TG) high-density lipoprotein cholesterol (HDL-C), uric acid (UA) and blood glucose (BG) were measured under a fasting condition within 24 hours after admission. Low-density lipoprotein cholesterol (LDL-C) level was calculated by the Friedewald formula, and those with TG levels $\geqq 400 \mathrm{mg} / \mathrm{dl}$ were excluded (14). The history of use of antihypertensive and/or antilipidemic drugs was also evaluated. The presence of diabetes mellitus was defined as the diagnosis made at the first examination by $75 \mathrm{~g}$ oral glucose tolerance test and those who had been treated for diabetes mellitus.

\section{Statistical analysis}

Statistical analysis was performed using SPSS 10.0J (Statistical Package for Social Science, Inc., Chicago, IL, USA). Differences among the mean levels of all categorical values were analyzed by Mann-Whitney U-test or $\chi^{2}$ test. Correlations between various characteristics and CCA diameter and 
Table 2. Correlation Coefficients between Common Carotid Artery Diameters and Intima-media Thickness and Cardiovascular Variables by Gender

\begin{tabular}{|c|c|c|c|c|}
\hline \multirow[b]{2}{*}{ Variable } & \multicolumn{2}{|c|}{ Common carotid artery diameters } & \multicolumn{2}{|c|}{ Common carotid intima-media thickness } \\
\hline & $\begin{array}{c}\text { Men } \\
\mathrm{N}=351 \\
\mathrm{r}_{\mathrm{s}} \text { (p-value) }\end{array}$ & $\begin{array}{c}\text { Women } \\
N=474 \\
r_{s} \text { (p-value) }\end{array}$ & $\begin{array}{c}\text { Men } \\
\mathrm{N}=351 \\
\mathrm{r}_{\mathrm{s}} \text { (p-value) }\end{array}$ & $\begin{array}{c}\text { Women } \\
N=474 \\
r_{8} \text { (p-value) }\end{array}$ \\
\hline Age, years & $0.115(0.031)$ & $0.153(0.001)$ & $0.458(<0.001)$ & $0.377(<0.001)$ \\
\hline Body mass indext, $\mathrm{kg} / \mathrm{m}^{2}$ & $0.310(<0.001)$ & $0.221(<0.001)$ & $0.076(0.155)$ & $-0.001(0.988)$ \\
\hline Smoking statusł, pack $\cdot$ years & $0.102(0.057)$ & $-0.015(0.744)$ & $0.115(0.032)$ & $0.028(0.550)$ \\
\hline Alcohol consumption, $g /$ day & $0.250(<0.001)$ & $0.021(0.642)$ & $0.039(0.471)$ & $-0.059(0.201)$ \\
\hline Systolic blood pressure, $\mathrm{mmHg}$ & $0.242(<0.001)$ & $0.155(0.001)$ & $0.262(<0.001)$ & $0.206(<0.001)$ \\
\hline Diastolic blood pressure, $\mathrm{mmHg}$ & $0.099(0.063)$ & $-0.017(0.712)$ & $-0.007(0.893)$ & $-0.029(0.531)$ \\
\hline Anthypertensive drug use (Yes=1, No=0) & $0.189(<0.001)$ & $0.205(<0.001)$ & $0.233(<0.001)$ & $0.202(<0.001)$ \\
\hline Total cholesterol, mg/dl & $-0.061(0.258)$ & $0.005(0.915)$ & $0.046(0.392)$ & $0.094(0.041)$ \\
\hline Triglyceride, mg/dl & $0.072(0.179)$ & $0.108(0.019)$ & $0.010(0.857)$ & $0.031(0.499)$ \\
\hline LDL-cholesterol, mg/dl & $-0.072(0.177)$ & $-0.002(0.959)$ & $0.131(0.014)$ & $0.131(0.004)$ \\
\hline HDL-cholesterol, mg/dl & $-0.022(0.676)$ & $-0.020(0.666)$ & $-0.153(0.004)$ & $-0.087(0.057)$ \\
\hline Antilipidemic drug use (Yes=1, No=0) & $0.035(0.518)$ & $-0.011(0.812)$ & $0.109(0.041)$ & $-0.014(0.769)$ \\
\hline Uric acid, mg/dl & $0.099(0.063)$ & $0.181(<0.001)$ & $0.124(0.020)$ & $0.155(0.001)$ \\
\hline Blood glucose, mg/dl & $-0.033(0.533)$ & $-0.032(0.481)$ & $0.007(0.903)$ & $0.004(0.929)$ \\
\hline Diabetes mellitus (Yes $=1, \mathrm{No}=0$ ) & $-0.066(0.217)$ & $-0.013(0.777)$ & $0.119(0.026)$ & $0.063(0.171)$ \\
\hline
\end{tabular}

$r_{\mathrm{s}}$, Spearman's correlation coefficient. †Body mass index was calculated using weight in kilograms divided by the square of height in meters. $\neq$ Smoking status: daily consumption (packs) $\times$ duration of smoking (years).

Table 3. Multiple Regression Analysis of Common Carotid Artery Diameters and Intima Mediathickness with Confound Variables as Independent Factors by Gender

\begin{tabular}{|c|c|c|c|c|}
\hline \multirow[b]{2}{*}{ Variable } & \multicolumn{2}{|c|}{ Carotid artery diameters } & \multicolumn{2}{|c|}{ Carotid intima-media thickness } \\
\hline & $\begin{array}{c}\text { Men } \\
N=351 \\
\beta \text { (p-value) }\end{array}$ & $\begin{array}{c}\text { Women } \\
N=474 \\
\beta \text { (p-value) }\end{array}$ & $\begin{array}{c}\text { Men } \\
\mathrm{N}=351 \\
\beta \text { (p-value) }\end{array}$ & $\begin{array}{c}\text { Women } \\
\mathrm{N}=474 \\
\beta \text { (p-value) }\end{array}$ \\
\hline Age, years & $0.112(0.034)$ & $0.194(<0.001)$ & $0.435(<0.001)$ & $0.382(<0.001)$ \\
\hline Body mass indext, $\mathrm{kg} / \mathrm{m}^{2}$ & $0.369(<0.001)$ & $0.194(<0.001)$ & $-0.014(0.771)$ & $-0.024(0.596)$ \\
\hline Smoking statusł, pack·years & $0.101(0.039)$ & $0.018(0.702)$ & $0.071(0.116)$ & $0.065(0.130)$ \\
\hline Alcohol consumption, $g /$ day & $0.238(<0.001)$ & $0.056(0.222)$ & $0.030(0.507)$ & $-0.046(0.284)$ \\
\hline Systolic blood pressure, $\mathrm{mmHg}$ & $0.124(0.050)$ & $0.127(0.013)$ & $0.240(<0.001)$ & $0.228(<0.001)$ \\
\hline Diastolic blood pressure, $\mathrm{mmHg}$ & $-0.033(0.587)$ & $-0.039(0.447)$ & $-0.143(0.011)$ & $-0.102(0.032)$ \\
\hline Anthypertensive drug use (Yes=1, №=0) & $0.043(0.404)$ & $0.130(0.005)$ & $0.063(0.184)$ & $0.092(0.030)$ \\
\hline Triglyceride, mg/dl & $-0.045(0.411)$ & $0.061(0.223)$ & $-0.074(0.138)$ & $-0.009(0.852)$ \\
\hline LDL-cholesterol, mg/dl & $-0.075(0.131)$ & $-0.082(0.093)$ & $0.148(0.001)$ & $0.128(0.005)$ \\
\hline HDL-cholesterol, mg/dl & $0.037(0.458)$ & $0.053(0.258)$ & $-0.090(0.053)$ & $-0.065(0.137)$ \\
\hline Antilipidemic drug use (Yes $=1, N_{0}=0$ ) & $0.004(0.927)$ & $-0.046(0.308)$ & $0.026(0.557)$ & $0.013(0.754)$ \\
\hline Uric acid, mg/dl & $0.112(0.021)$ & $0.086(0.057)$ & $0.097(0.032)$ & $0.077(0.067)$ \\
\hline Blood glucose, mg/dl & $-0.074(0.183)$ & $-0.042(0.394)$ & $-0.007(0.896)$ & $-0.058(0.200)$ \\
\hline Diabetes mellitus $(Y e s=1, N o=0)$ & $-0.071(0.202)$ & $-0.036(0.480)$ & $0.129(0.013)$ & $0.095(0.043)$ \\
\hline Multiple $R$ & 0.529 & 0.383 & 0.619 & 0.513 \\
\hline Adjusted $R^{2}$ & $0.279(<0.001)$ & $0.147(<0.001)$ & 0.383 & $0.263(<0.001)$ \\
\hline
\end{tabular}

†Body mass index was calculated using weight in kilograms divided by the square of height in meters. $\neq$ Smoking status: daily consumption (packs) $\times$ duration of smoking (years). LDL, low-density lipoprotein; HDL, high-density lipoprotein.

IMT were made using Spearman's correlation test. The relation between CCA diameter and IMT and cardiovascular confounding factors were examined by stepwise multiple linear regression analysis. After the observation of the association between carotid IMT and diameters, ANCOVA was performed with the use of a general linear model approach to determine the association between cardiovascular confounding factors and CCA diameters. In these analyses, CCA diameters were considered the dependent variables, four ranges of each variable were considered the fixed factors, and both carotid IMT and plaque were added as covariates. A value of $\mathrm{p}<0.05$ was considered significant.

\section{Results \\ Clinical and biochemical characteristics of par- ticipants by gender}

Table 1 shows the background characteristics of participants by gender. Several characteristics differed among men and women. Smoking status $(\mathrm{p}<0.001)$, alcoholic consumption $(\mathrm{p}<0.001)$, UA $(\mathrm{p}<0.001)$ and CCA diameter $(<0.001)$ were higher in men, but age $(\mathrm{p}<0.001)$, prevalence of antihypertensive drug use $(p=0.002)$, LDL-C $(p<0.001)$ and 

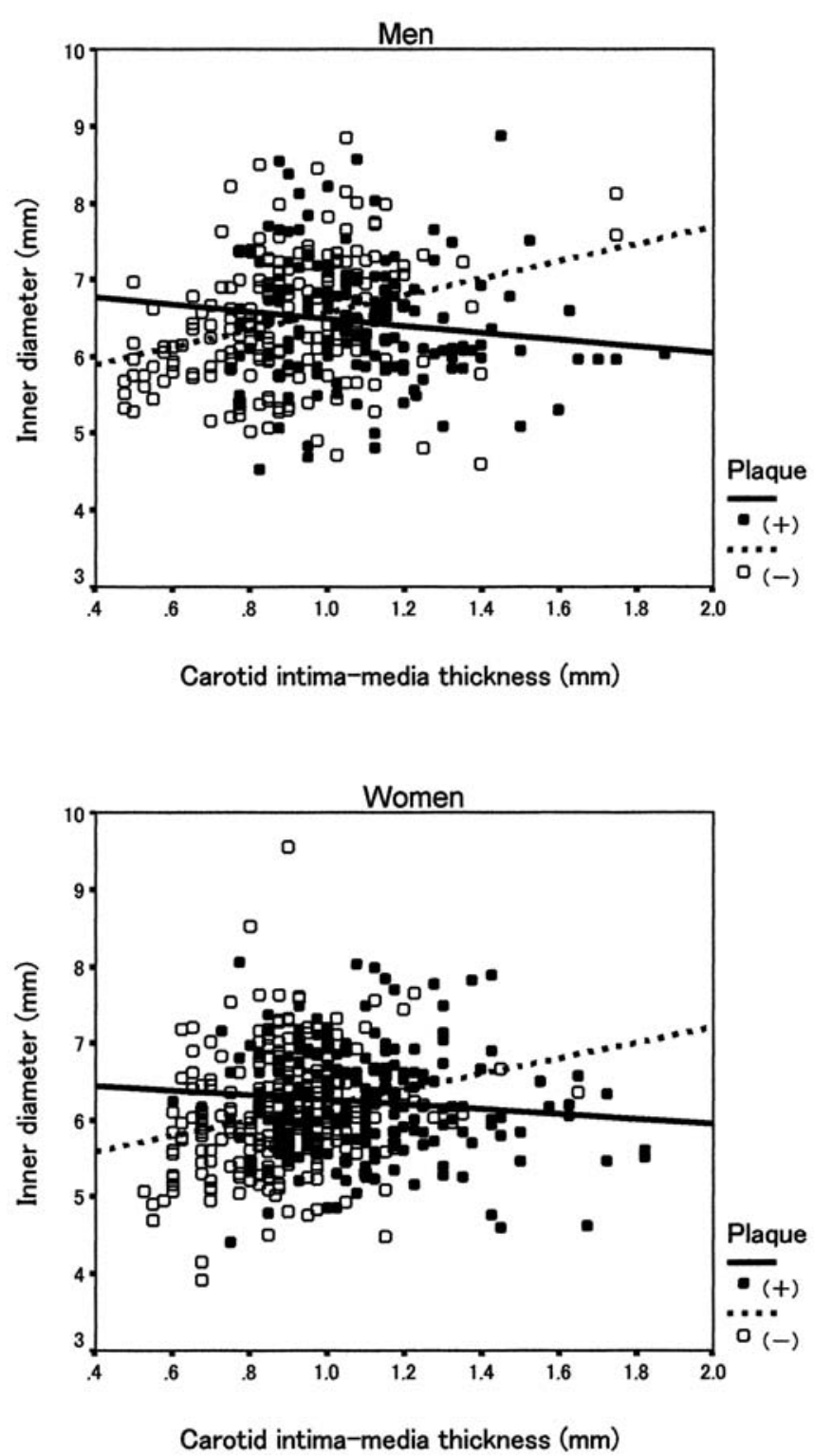

Figure 1. Regression line between carotid intima-media thickness and diameter with or without plaque by gender. Men without plaque, $r=0.302(p<0.001)$; men with plaque, $r=-$ 0.124 ( $p=123)$. Women without plaque, $r=0.230 \quad(p<0.001)$; women with plaque, $r=-0.099$ ( $p=0.149)$. Analysis of covariance showed that the two regression lines were significantly different in both men $(F=16.4 ; p<0.001)$ and women $(F=15.0$; $\mathbf{p}<0.001)$.

HDL-C $(\mathrm{p}<0.001)$ were significantly lower. There were no inter-group differences in BMI, SBP, DBP, TG, prevalence of antilipidemic drug use, BG, carotid IMT, presence of carotid plaque and history of diabetes mellitus or atherosclerotic disease.

\section{Correlation coefficients between common ca- rotid artery diameters and cardiovascular vari- ables by gender}

Table 2 shows the correlation coefficient between CCA diameters and IMT and cardiovascular variables by gender.
CCA diameters were significantly correlated with age $(\mathrm{p}=$ $0.031)$, BMI $(\mathrm{p}<0.001)$, alcohol consumption $(\mathrm{p}<0.001)$, SBP $(p<0.001)$ and prevalence of antihypertensive drug use $(\mathrm{p}<0.001)$ in men, and with age $(\mathrm{P}=0.001)$, BMI $(\mathrm{p}<0.001)$, SBP $(\mathrm{p}=0.001)$, prevalence of antihypertensive drug use $(\mathrm{p}<$ $0.001)$, TG $(\mathrm{p}=0.019)$ and UA $(\mathrm{p}<0.001)$ in women. Carotid IMT was significantly correlated with age $(\mathrm{p}<0.001)$, smoking status $(\mathrm{p}=0.032), \operatorname{SBP}(\mathrm{p}<0.001)$, antihypertensive drug use $(p<0.001)$, LDL-C $(p=0.014)$, HDL-C $(p=0.004)$, antilipidemic drug use $(\mathrm{p}=0.041)$, uric acid $(\mathrm{p}=0.020)$ and presence of diabetes mellitus $(\mathrm{p}=0.026)$ in men, and with age $(\mathrm{p}<0.001)$, SBP $(\mathrm{p}<0.001)$, antihypertensive drug use $(\mathrm{p}$ $<0.001)$, T-C $(\mathrm{p}=0.041)$, LDL-C $(\mathrm{p}=0.004)$ and UA $(\mathrm{p}=$ $0.001)$ in women.

\section{Multiple regression analysis of common carotid artery diameters with confound variables as in- dependent factors by gender}

To find independently confounding factors for CCA diameters and IMT, multiple linear regression analyses were performed (Table 3). In the analyses, after controlling for traditional cardiovascular risk factors, a significant correlation was still found between CCA diameters and age $(\mathrm{p}=$ 0.034), BMI $(\mathrm{p}<0.001)$, smoking status $(\mathrm{p}=0.039)$, alcohol consumption $(<0.001)$ and UA $(\mathrm{p}=0.021)$ in men, and between CCA diameters and age $(<0.001)$, BMI $(\mathrm{p}<0.001)$, SBP $(p=0.013)$ and antihypertensive drug use $(p=0.005)$ in women. Carotid IMT was significantly associated with age $(<0.001), \operatorname{SBP}(<0.001), \operatorname{DBP}(\mathrm{p}=0.011)$, LDL-C $(\mathrm{p}=0.001)$, UA $(p=0.032)$ and presence of diabetes mellitus $(p=0.013)$ in men, and with age $(<0.001), \operatorname{SBP}(<0.001), \operatorname{DBP}(\mathrm{p}=$ $0.032)$, antihypertensive drug use $(\mathrm{p}=0.030)$, LDL-C ( $\mathrm{p}=$ $0.005)$ and presence of diabetes mellitus $(p=0.043)$ in women.

\section{Regression line between carotid intima-media thickness and diameter with or without plaque by gender}

Since previous studies demonstrated a difference between those with and those without plaque in an association between carotid IMT and diameters (15-17). We also tested for a possible influence of plaque on the carotid enlargement related to the IMT levels. In those without plaque, the slope of regression line between carotid IMT and diameter was significantly sleeper than those with plaque, and the coefficients of regression were significantly different in both men $(\mathrm{F}=16.4 ; \mathrm{p}<0.001)$ and women $(\mathrm{F}=15.0 ; \mathrm{p}<0.001)$ (Fig. 1).

\section{Common carotid artery diameters in a different range of age, body mass index, smoking status, alcoholic consumption, systolic blood pressure and uric acid by gender}

In a subanalysis, we decided to test the influence of the cardiovascular confounding factors mentioned in Table 4 on carotid diameters, taking into account the influence of IMT and plaque presence. After adjustment for carotid IMT and 
Table 4. Common Carotid Artery Diameters in Different Range of Age, Body Mass Index, Smoking Status, Alcoholic Consumption, Systolic Blood Pressure and Uric Acid by Gender

\begin{tabular}{|c|c|c|c|c|c|}
\hline Variable & Range & No & $\begin{array}{c}\text { Men } \\
\mathrm{N}=351 \\
\text { CCA diameter } \\
(\mathrm{mm})\end{array}$ & No & $\begin{array}{c}\text { Women } \\
\mathrm{N}=474 \\
\text { CCA diameter } \\
(\mathrm{mm})\end{array}$ \\
\hline \multicolumn{6}{|l|}{ Age, years } \\
\hline Lowest & $<55$ & 40 & $5.98 \pm 0.13$ & 21 & $5.69 \pm 0.16$ \\
\hline $2^{\circ}$ & $55-64$ & 42 & $6.27 \pm 0.12$ & 42 & $5.93 \pm 0.11$ \\
\hline $3^{\circ}$ & $65-74$ & 116 & $6.69 \pm 0.07$ & 140 & $6.18 \pm 0.06$ \\
\hline \multirow[t]{2}{*}{ Upper } & $\geqq 75$ & 153 & $6.44 \pm 0.07$ & 271 & $6.21 \pm 0.05$ \\
\hline & & & $p<0.001$ & & $p=0.005$ \\
\hline \multicolumn{6}{|l|}{ Body mass indext, $\mathrm{kg} / \mathrm{m}^{2}$} \\
\hline Lowest & $<20.0$ & 91 & $6.14 \pm 0.08$ & 140 & $5.96 \pm 0.06$ \\
\hline $2^{\circ}$ & $20.0-21.9$ & 82 & $6.34 \pm 0.08$ & 91 & $6.12 \pm 0.07$ \\
\hline $3^{\circ}$ & $22.0-24.9$ & 104 & $6.59 \pm 0.08$ & 130 & $6.19 \pm 0.06$ \\
\hline \multirow[t]{2}{*}{ Upper } & $25.0-50.0$ & 74 & $6.76 \pm 0.09$ & 113 & $6.38 \pm 0.07$ \\
\hline & & & $p<0.001$ & & $p<0.001$ \\
\hline \multicolumn{6}{|c|}{ Smoking status‡, pack ·years } \\
\hline Lowest & $<1.0$ & 112 & $6.40 \pm 0.07$ & 454 & $6.16 \pm 0.03$ \\
\hline $2^{\circ}$ & $1.0-29.9$ & 78 & $6.23 \pm 0.09$ & 10 & $6.96 \pm 0.23$ \\
\hline $3^{\circ}$ & $30.0-49.9$ & 84 & $6.55 \pm 0.09$ & 6 & $5.82 \pm 0.29$ \\
\hline \multirow[t]{2}{*}{ Upper } & $\geqq 50.0$ & 77 & $6.64 \pm 0.09$ & 4 & $6.66 \pm 0.36$ \\
\hline & & & $p=0.006$ & & $p=0.252$ \\
\hline \multicolumn{6}{|c|}{ Alcohol consumption, drink/day } \\
\hline Lowest & Never & 118 & $6.21 \pm 0.07$ & 462 & $6.15 \pm 0.03$ \\
\hline $2^{\circ}$ & $0.1-2.0$ & 110 & $6.44 \pm 0.07$ & 9 & $6.13 \pm 0.24$ \\
\hline $3^{\circ}$ & $2.1-3.9$ & 65 & $6.73 \pm 0.09$ & 2 & $7.23 \pm 0.51$ \\
\hline \multirow[t]{2}{*}{ Upper } & $\geqq 4.0$ & 26 & $6.95 \pm 0.15$ & 0 & - \\
\hline & & & $p<0.001$ & & $p=0.107$ \\
\hline \multicolumn{6}{|c|}{ Systolic blood pressure, mmHg } \\
\hline Lowest & $<120$ & 95 & $6.23 \pm 0.08$ & 97 & $5.99 \pm 0.07$ \\
\hline $2^{\circ}$ & $120-134$ & 86 & $6.35 \pm 0.08$ & 142 & $6.13 \pm 0.06$ \\
\hline $3^{\circ}$ & $135-149$ & 76 & $6.59 \pm 0.09$ & 108 & $6.20 \pm 0.07$ \\
\hline \multirow[t]{2}{*}{ Upper } & $\geqq 150$ & 94 & $6.65 \pm 0.08$ & 127 & $6.26 \pm 0.06$ \\
\hline & & & $p=0.001$ & & $p=0.047$ \\
\hline \multicolumn{6}{|l|}{ Uric acid, mg/dl } \\
\hline Lowest & $<4.0$ & 60 & $6.36 \pm 0.10$ & 142 & $5.96 \pm 0.06$ \\
\hline $2^{\circ}$ & $4.0-4.9$ & 81 & $6.40 \pm 0.09$ & 122 & $6.16 \pm 0.06$ \\
\hline $3^{\circ}$ & $5.0-6.2$ & 99 & $6.46 \pm 0.08$ & 111 & $6.29 \pm 0.07$ \\
\hline \multirow[t]{2}{*}{ Upper } & $\geqq 6.3$ & 111 & $6.53 \pm 0.08$ & 99 & $6.27 \pm 0.07$ \\
\hline & & & $p=0.515$ & & $p=0.001$ \\
\hline
\end{tabular}

Diameter values are mean \pm standard error; all values are adjusted carotid intima-media thickness and plaque presence. †Body mass index was calculated using weight in kilograms divided by the square of height in meters. ₹Smoking status: daily consumption (packs) $\times$ duration of smoking (years).

plaque, associations with carotid diameters still persisted for age $(\mathrm{p}<0.001)$, BMI $(\mathrm{p}<0.001)$, smoking status $(\mathrm{p}=0.006)$, alcohol consumption $(\mathrm{p}<0.001)$ and $\operatorname{SBP}(\mathrm{p}=0.001)$ in men, and age $(\mathrm{p}=0.005)$, BMI $(\mathrm{p}<0.001)$, SBP $(\mathrm{p}=0.047)$ and UA $(\mathrm{p}=0.001)$ in women. All these differences were calculated after Bonferroni correction for multiple comparisons.

\section{Discussion}

The main findings of the present B-mode ultrasonographic study were that the CCA diameter was closely related to modifications of the arterial wall. CCA diameter was positively associated with many cardiovascular risk fac- tors, such as age, BMI, pack-years of smoking, SBP and antihypertensive drug use. Furthermore, this study revealed that less expected factors such as alcohol consumption in men and UA in women contributed independently to increased CCA diameter. This association was independent of IMT and the presence of plaque, and was present both in men and women, suggesting that adaptive remodeling of the arterial stimuli comes even before plaque formation. In Japan, to our knowledge, only a few large cross-sectional studies investigating factors related to increase in size of CCA diameter have been reported (4), but most such studies, other than the Suita study (4), were restricted to a limited age range $(10,12,18,19)$. 
In this study, the impact of cardiovascular confounding risk factors on carotid enlargement was evaluated by taking into account the influence of arterial wall thickness and plaque. Vessel diameter generally increases with age. However, independent of age, all peripheral arteries dilate in response to intima-media thickening and plaque formation in the stage of early atherosclerotic plaque formation. It is concluded that this adaptive response occurs at the site of the lesion to preserve luminal area $(20,21)$. Although in this study, CCA diameter was significantly increased with increased carotid IMT in those without plaque formation, but not increased in those with plaque formation. Crouse and coworkers studied B-mode ultrasound to quantify the relation of arterial lumen diameter to age, arterial wall thickness, and arterial size of the carotid artery in 13,711 members of the Atherosclerosis Risk in Communities (ARIC) cohort (18). The internal carotid arterial wall thickness was reported to be associated positively with age, but the lumen diameter of the internal carotid artery was smaller in older individuals. The lumen of the internal carotid artery was uniformly progressively narrower with increasing wall thickness. Mannami et al also reported that the carotid outer diameter may dilate to compensate for thickened IMT of the CCA, but the carotid inner diameter may not dilate perhaps because it is confounded by the thickness of the IMT layer (11). As shown in Fig. 1, an association between CCA diameter and IMT was different between those with plaque and those without plaque, and the present data suggests that significant interactions of carotid IMT and plaque exist on CCA diameter.

On the other hand, the association between CCA diameter and some cardiovascular confounding risk factors (ie. blood pressure, smoking, LDL-C) has been previously assessed in a few studies. Our results are in part consistent with those of previous studies. In the EVA (Etude sur le vieillissement arte riel) study, male sex, body height and weight, common IMT, plaque score, SBP, and alcohol consumption were related to CCA diameters, whereas LDL-C was associated with smaller CCA diameters (10). In the Suita study, a positive association both in men and women was found between CCA diameters and age, BMI, SBP, smoking, alcohol consumption and IMT, whereas a negative association was observed between T-C and CCA diameters (11). In a community-based study of middle-aged women, CCA diameters were directly related to age, BMI, SBP, DBP and total radical antioxidant potential (22). Especially, increased SBP appeared to be one of the most important and strongest correlates of CCA diameter (10). We also showed that SBP and IMT were significantly associated with enlargement of the carotid artery, and CCA diameters were enlarged with an increased BP level both in men and women and this association persisted even after controlling for wall thickness. These data suggest that prolonged blood pressure causes enlargement of arterial diameter and that the CCA diameters might be a useful marker of high blood pressure (11).

In addition, our study showed reasonable results that BMI is strongly correlated with CCA diameter and that the CCA diameter of men is larger than that of women. These findings are consistent with other studies $(10,12,19)$ and seem to be morphologically and physically natural phenomenon (11).

The present study also showed that alcohol consumption is significantly associated with enlargement of CCA diameter in men. There are few data concerning the relation of alcohol consumption and arterial wall characteristics. The mechanisms which may link alcohol consumption to carotid enlargement are unknown. However, previous studies (10, $11,23)$ are similar to our results. The positive association of alcohol consumption with CCA diameter may reflect the ability of alcohol to maintain adaptive enlargement to preserve lumen area. Adaptive changes in CCA diameter produced by changes in shear stress or blood flow are partially endothelium dependent (24). Alcohol (particularly red wine) increases endothelial nitric oxide synthase (eNOS) expression and subsequent endothelial NO release. Increased active eNOS levels may protect the development of endothelial dysfunction and atherosclerosis (25). Moreover, ethanol suppresses endothelium-dependent vasorelaxation without apparent removal of the endothelial cells. The compromised relaxant capacity of the endothelium after ethanol and the resultant intensification of the vasoconstrictor response to norepinephrine may contribute to the development of vascular diseases such as hypertension and stroke (26).

The question of serum UA as an independent risk factor in subjects with atherosclerosis remains controversial. Our previous study shows that serum UA is a risk factor or marker for ultrasonographically determined IMT (27). However, few cross-sectional studies have reported a relationship between UA and CCA diameters. It was reported that a higher serum UA concentration is associated with elevated total serum antioxidant capacity among individuals with atherosclerosis, and hyperuricemia might be a compensatory mechanism to counteract oxidative damage related to atherosclerosis and aging in humans (28).

We need to be aware of the limitations in interpreting the present results. Since all participants were hospitalized patients, we could not eliminate the possibility of the effect of underlying diseases and medication. The present data include a cross-sectional nature, thereby precluding temporality and casual inference. However, there are also some advantages of this study design that are worth noting. First, we were able to examine an extensive array of atherosclerotic risk factors in relation to CCA diameters. Second, the relatively large sample size enabled assessment of associations in CCA diameters and atherosclerotic risk factors. Third, noninvasive ultrasound imaging of the carotid IMT and lumen diameters provided a direct measure of atheroma development, thus enabling study of the association of atherosclerotic risk factors with CCA diameters, without the interference of thrombosis.

In conclusion, this study showed the relationships of CCA diameters with conventional cardiovascular risk factors and 
alcohol consumption after adjustment for carotid IMT and plaque. These results need to be confirmed in a younger population, and longitudinal studies are necessary to determine their significance with regard to the progression of atherosclerosis.

This work was supported in part by a grant-in-aid from the Foundation for Development of Community (2005).

\section{References}

1. Pignoli P, Tremoli E, Poli A, Oreste P, Paoletti R. Intimal plus medial thickness of the arterial wall: a direct measurement with ultrasound imaging. Circulation 74: 1399-1406, 1986.

2. Salonen JT, Salonen R. Ultrasonographically assessed carotid morphology and the risk of coronary heart disease. Arterioscler Throm 11: 1245-1249, 1991.

3. Sidhu PS, Desai SR. A simple and reproducible method for assessing intimal-medial thickness of the common carotid artery. $\mathrm{Br}$ J Radiol 70: 85-89, 1997.

4. Mannami T, Konishi M, Baba S, Nishi N, Terao A. Prevalence of asymptomatic carotid atherosclerotic lesions detected by highresolution ultrasonography and its relation to cardiovascular risk factors in the general population of a Japanese city: the Suita study. Stroke 28: 518-525, 1997.

5. Mannami T, Baba S, Ogata J. Strong and significant relationships between aggregation of major coronary risk factors and the acceleration of carotid atherosclerosis in the general population of a Japanese city: the Suita Study. Arch Intern Med 160: 2297-2303, 2000.

6. Tatsukawa M, Sawayama Y, Maeda N, et al. Carotid atherosclerosis and cardiovascular risk factors: a comparison of residents of a rural area of Okinawa with residents of a typical suburban area of Fukuoka, Japan. Atherosclerosis 172: 337-343, 2004.

7. Bots ML, Grobbee DE. Intima media thickness as a surrogate marker for generalised atherosclerosis. Cardiovasc Drugs Ther 16: 341-351, 2002.

8. Kastelein JJ, Wiegman A, de Groot E. Surrogate markers of atherosclerosis: impact of statins. Atheroscler Suppl 4: 31-36, 2003.

9. Espeland MA, O'leary DH, Terry JG, Morgan T, Evans G, Mudra H. Carotid intimal-media thickness as a surrogate for cardiovascular disease events in trials of HMG-CoA reductase inhibitors. Curr Control Trials Cardiovasc Med 6: 3, 2005.

10. Bonithon-Kopp C, Touboul PJ, Berr C, Magne C, Ducimetiere P. Factors of carotid arterial enlargement in a population aged 59 to 71 years: the EVA study. Stroke 27: 654-660, 1996.

11. Mannami T, Baba S, Ogata J. Potential of carotid enlargement as a useful indicator affected by high blood pressure in a large general population of a Japanese city: the Suita study. Stroke 31: 2958-2965, 2000.

12. Polak JF, Kronmal RA, Tell GS, et al. Compensatory increase in common carotid artery diameter. Relation to blood pressure and artery intima-media thickness in older adults. Cardiovascular Health Study. Stroke 27: 2012-2015, 1996.

13. Kawamoto R, Doi T, Tokunaga H, Konishi I. Risk factor and common carotid intima-media thickness assessed by ultrasonography-influence of local plaque on the relationship. Ultrasound International 7: 3-11, 2001.

14. Friedewald WT, Levy RI, Fredrickson DS. Estimation of the con- centration of low-density lipoprotein cholesterol in plasma, without use of the preparative ultracentrifuge. Clin Chem 18: 499-502, 1972.

15. Glagov S, Weisenberg E, Zarins CK, Stankunavicius R, Kolettis GJ. Compensatory enlargement of human atherosclerotic coronary arteries. N Engl J Med 316: 1371-1375, 1987.

16. Pasterkamp G, Wensing PJW, Post MJ, Hillen B, Mali WPTM, Borst C. Paradoxical arterial wall shrinkage may contribute to luminal narrowing of human atherosclerotic femoral arteries. Circulation 91: 1444-1449, 1995.

17. Labropoulos N, Zarge J, Mansour MA, Kang SS, Baker WH. Compensatory arterial enlargement is a common pathobiologic response in early atherosclerosis. Am J Surg 176: 140-143, 1998.

18. Crouse JR, Goldbourt U, Evans G, et al. Arterial enlargement in the atherosclerosis risk in communities (ARIC) cohort. In vivo quantification of carotid arterial enlargement. The ARIC Investigators. Stroke 25: 1354-1359, 1994.

19. Jensen-Urstad K, Jensen-Urstad M, Johansson J. Carotid artery diameter correlates with risk factors for cardiovascular disease in a population of 55-year-old subjects. Stroke 30: 1572-1576, 1999.

20. Steinke W, Els T, Hennerici M. Compensatory carotid artery dilatation in early atherosclerosis. Circulation 89: 2578-2581, 1994.

21. Labropoulos N, Zarge J, Mansour MA, Kang SS, Baker WH. Compensatory arterial enlargement is a common pathobiologic response in early atherosclerosis. Am J Surg 176: 140-143, 1998.

22. Iannuzzi A, De Michele M, Panico S, et al. Radical-trapping activity, blood pressure, and carotid enlargement in women. Hypertension 41: 289-296, 2003.

23. Zureik M, Gariepy J, Courbon D, et al. Alcohol consumption and carotid artery structure in older French adults: the Three-City Study. Stroke 35: 2770-2775, 2004.

24. Clowes AW, Berceli SA. Mechanisms of vascular atrophy and fibrous cap disruption. Ann N Y Acad Sci 902: 153-161, 2000.

25. Leikert JF, Rathel TR, Wohlfart P, Cheynier V, Vollmar AM, Dirsch VM. Red wine polyphenols enhance endothelial nitric oxide synthase expression and subsequent nitric oxide release from endothelial cells. Circulation 106: 1614-1617, 2002.

26. Criscione L, Powell JR, Burdet R, Engesser S, Schlager F, Schoepfer A. Alcohol suppresses endothelium-dependent relaxation in rat mesenteric vascular beds. Hypertension 13: 964-967, 1989.

27. Kawamoto R, Tomita H, Oka Y, Kodama A, Otsuka N, Kamitani A. Association between uric acid and carotid atherosclerosis in elderly persons. Intern Med 44: 787-793, 2005.

28. Nieto FJ, Iribarren C, Gross MD, Comstock GW, Cutler RG. Uric acid and serum antioxidant capacity: a reaction to atherosclerosis? Atherosclerosis 148: 131-139, 2000.

(C) 2006 The Japanese Society of Internal Medicine

http://www.naika.or.jp/imindex.html 